\title{
An ethnography of old-age homes and senior-citizens in Devghat
}

By Sharma Sharada Devi

M/S Sharma is pursuing PhD can be contacted at: sharmasharada0@gmail.com

\begin{abstract}
Old-age homes are Sanyas Ashrams in Vedic philosophy. Sanyas Ashram is the preparation of death and it teaches the art of death. It is the university of art of death of old and experienced people who can share the knowledge and experiences of their lifetime achievements. The main objective of the study is to examine the socio economic and cultural status of old-age people living in Deveghat pilgrimage areas. It is a mini ethnography study based on field visit observation, focus group discussion and unstructured interview. I conclude that the old-age homes of Devghat are normal in-terms of the lifestyle of the elderly living there, their happiness level and the facility provided to them. Lastly the major reasons behind them coming to the old-age home was rather found to be in a mixed bag form as some came there due to the social reasons and economic reasons and some due to their faith in god and in belief of getting peace after death. But it has long way to go to make like a heaven type of Sanyas Ashram. At least it must be like a Vrindavan with entire worldly facilities of learning and sharing of knowledge production university.
\end{abstract}

Keywords: Devghat, Mini ethnography, Old-age homes, Senior citizen

\section{Background}

If there is birth, there must be death. Everyone has to die. Human birth is the phenomenon of 9 months but death is on one can predict. That is why, old-age can be considered as a natural phenomenon of human life cycle, that starts after the age of the person crosses 60 years. The term "old" can be associated with physical incapacity, biological deterioration or disabilities or even psychological factors. Facial expressions, hairs, body structure and physical situation are external factors introducing an old-age (Newman, 2003). Therefore, the old-age is generally the life after 60 years. Thus, people with having psychological traditional thinking, gray hair, wrinkled skin and weak eye ear power and weak body. Purna Bahadur from Kaski living in Devghat oldage home told his sad story of bygone days and reason of leaving home. His eyes were full of tear and recited, "Budho bhayo sab ranga gayo, angan bhayo paradesh - being an old and weak frontward of home became abroad. Ethnography is essentially the study of people and their interactions through observation. It was originally developed as a subset of anthropology, and used as a technique to determine the cultural and social norms of different peoples. So I have 
visited the Devghat pilgrim to explore the culture of lonely old-age people.

There are many stages in human life. The last stage is old-age. It starts after crossing middle age. In old-age; they are physically and mentally weak. Many older persons find living with their adult children to be more difficult then living alone and many do not have a choice and have to live separately from their adult children. In these circumstances old-age homes seems to be the choice for the older persons (Yadav, 2014). So old-age home is necessary because emotion of love and respect do not make them happy. In reality adult people have to work and earn they cannot have much time and skill to care old-age people. Old-age home should be like a university where people can get knowledge and share it for younger people.

Ageing is a worldwide phenomenon, which makes heavy demands on a variety of service delivering action to persons who are not anymore economically viable (Perold \& Muller, 2000). Old-age home is a specific home i.e. both public, private \& settlement where elderly people are given household care and environment with the services like food, lodging, nursing, health care, facilities. I can say that old-age home is a place that provides residential facilities to elderly people above the age of sixty, who are either under-privileged or do not have any body to look after them. So, it (Old-age Home) must be able to eliminate the psychology of loneliness and the feeling of poor and poverty of elderly.

The ageing people need to compare of a person of experience for sharing happiness and sorrows of their life. Similarly, elderly people are found to pass their time, predominantly pursuing religious activities or household works or visiting friends and relations or just taking rest. Recently the global eyesight is concentrated upon both problems and importance of elderly people. Some international convention was held in the field of ageing and international community self-esteem and human right. Nepal is also signature of the ageing convention and some effort has been made upon this field but neither there is sufficient nor are those implemented properly. Senior citizen policy and working plan 2002, National Plan of Action on ageing 2002 and published "The act of convention and social security of senior citizens, 2063" has provided the provision of the welfare of elderly people in Nepal (Ranjan, Bhattarai, \& Dutta, 2013). But still the local governments and provincial governments are not being able to address the issues of senior citizens.

Most of the women in old-age home spent their whole lives in doing house hold works and had no income for their livelihood which forced them to depend on their family and due to this reason; the female residents were more in members in old-age home as compared to their male. Widow older women were very far away from government schemes. Probably old-age is the age when a 
human being feels more in need of someone to interact with and someone to share his/her feelings with (Yadav, 2014). Old-age home can be understood as:

"Place which provide comprehensive package services as, food, lodging, nursing care, recreation facilities, physiotherapy and health care addressing human needs of elderly period. Provide residential care services targeting minor geriatric health and social problems focusing on nursing care for elderly people. Create home environment responding daily needs that makes comfortable for elderly people. Day care for the elderly, etc. The need of old-age home is growing more drastically in the present time as one out of 10 people are growing as old-aged people and the elderly growth rate is 6.5\%" (Yadav, 2014).

After people reach the $4^{\text {th }}$ stage of their life, they want people's care i.e. their family members care. The old-aged peoples and new generation people have differentiated though that makes them differ in their behavior and thinking. This difference creates an interaction among these two generations which creates a separation in their day to day life. This difference creates a situation of insecurity in old-aged peoples. On the other hand, the new generation people have a busy lifestyle and they don't want to live in old-aged ways. So, this difference in thoughts and interaction leads the old-aged people to live in old-aged homes (Gautam, 2010).

Devghat is a one of the famous religious and cultural centers in province three of Nepal. At the time of the 1991 Nepal census it had a population of 5786 people living in 1132 individual households. It is located at the junction of Seti Gandaki and Krishna Gandaki rivers. It is one of the holiest places in Hindu mythology as well as a holy place for Hindu gods. It is located 7 kilometers from Narayanghat, 20 kilometers from Sauraha and 150 kilometers southwest of the capital city Kathmandu. It is the center of or junction of Bishnu and Shiva devotees. It is the meeting point of two rivers means meeting point of two cultures of Baishanb and Shaisab.

In the present context of Nepal, the social system is changing. The family system and the family orientation has been directly affected by the entry of modernization. The people's change in lifestyle has created a condition in which elderly are deprived of the care and love that they were getting in the past times from their family member due to busier lifestyle or change of perception to the elderly from a sign of god to general common and unproductive people. This change in the perception or busyness in people have created a condition where the elderly have to go the oldage home to live the rest of their life. With this study readers being able to see for the facilities and hospitability that is provided to the elderly people in the old-age home. These two factors can be generalized to find out the result of the idea on the reason of sustainability of the old-age 
home. Other than the hospitability and facilities provided to the elderly people, the ratio of male and female elderly living in the old-age home were visualized to find out the which gender is more under pressure in the family system of changing Nepal and the role of society, economy as well as culture in determining their living pattern and living style, their level of care, their level of satisfaction in old-age homes as well as individual houses. The reasons behind the study of oldage home and elderly was to identify the status of elderly now and in the past, the reasons behind them to live and not to live in the old-age home, the facilities provided to the elderly people and the impact of modernization in elderly people of Nepal.

Due to the high costs of frail institutionalized care, the empowerment of the community in taking care of their elderly, in a culturally sensitive manner, should also receive attention. The rights of the elderly must, however, also be respected (Perold \& Muller, 2000). It shows that the culture of respecting old people is reducing globally. With the change those took place in Nepalese, social life has extended the requirement of elderly support. Current trend of youth migration from rural area to foreign countries and internal urban centers, consideration of elderly with weak health (health includes Dementia, Alzheimer, sugar, pressure, etc.) and economic problem as burden in the family and idea of nuclear family has created a situation where elderly is sent to individual care homes. Breaking down of joint family, rural-urban migration; mostly among the population of higher education, industrialization etc. have generated the requirement of elderly support in future. With the modernization, responsibility of providing economic security for dependent aged tends to be shifted from family to the state. However, the condition of old-age people in Nepal is pitiable. The youth are busy in their career development plan (Education, migration for Job) but old people are lonely either in home or in elderly home.

The youth migration in the foreign country e.g. Saudi Arabia, Qatar, Malaysia, Arab, Israel, Japan, etc. has caused the elderly people to be lonely in their homes. It brings many changes in human life of people such as physical mental, social, cultural, economic, etc. Recently the global eye-sight is concentrated upon both the problem and importance of the elderly people. The UN general assembly declared the year 1999 as the international year of older person. Most of the village of Nepal has experienced large mass of elderly people due to youth migration pattern from rural to urban. Modern generation also doesn't pay any attention towards elderly care. Elderly population is increased towards the lack of helping hand (Badal, 2015). There were 15 million elderly people in Nepal constituting 6.5 percent of the total population between 1991 and 2001. Rapid growing of industry modernization in world has led to change in the tradition of joint family in culture of Nepalese society with nuclear family system. This change in system has created a situation where the elderly is either left alone or are sent away from their home. 


\section{Objective and Methodology}

The research is solely based on the status of old-age home and the elderly people specially in Devghat area of Chitwan and Tanahun District. The objectives to match the context of the study is to examine the socio economic and cultural status of old-age people living in Deveghat pilgrimage areas.

A mini-ethnography, also known as a focused ethnography, is used when a field under investigation focuses on a specific or a narrow area of inquiry, particularly when time or monetary constraints are evident. Mini-ethnographies are prevalent within the medical field as well as marketing research and generally occur in less time than that of a full-scale ethnography and range in time frames of weeks to less than a year. The intent of mini-ethnography is for a researcher to understand the cultural norms, values, and roles as pertaining to what is remembered by participants as opposed to phenomenology which addresses lived experience, grounded theory which identifies new theory to explain phenomenon, or content analysis which studies human communication including websites, newspapers, paintings, or books. The common data collection methods often consist of fieldwork with direct observation, a focus group, a reflective journal, and unstructured interviews for triangulation (cross-examination) purposes. Thus the study was based on direct observation of old-age homes and elderly people as participants. I took the fieldwork notes, observation and focus group discussion and personal interview of old-age people.

\section{Reviews and Discussions}

This study has explored the existing issues, problems and conceptions of elderly of Devghat so it is a comprehensive guideline for policy makers, researchers and social workers. The existing status of the elderly people i.e. their economic status, social status and cultural status during the time of their residence in old-age home as well as the time when they were at their home. This idea is used to determine what kind of life they were living in the past and their lifestyle in the present time. This would also help in determining what kind of status of people were able to afford to live in what kind of old-age home i.e. either public, private home or private settlement. The research is also focus on the gender analysis where victims of family torture etc. be identified and determined. The facilities offered by the homes are helpful in determining the choice of peoples about elderly began in early 1960's. The recognition of longevity as one of the major future social problems by the world assembly on aging in Vienna, 1982 and the international plan of action on aging by the un general assembly provided a great motivation for aging research in India. Future, the assembly selected October $1^{\text {st }}$ as the international day for the elderly in 1990 and the international year of older persons in 1999 with the theme toward a society for all ages and an 
objective to increase the awareness of the fast-changing demographic trends of the elderly promote action policies and encourage research and information exchange. The increasing problem of the elderly within the changing society. Today, the elderly population is the main focus of the various social planners and service providers. Under the impact of industrialization and modernization, there is a simultaneous monitoring of the growing population with the study of aging in terms of socio-economic impact on family relation, health living condition and productivity (Gautam, 2010).

Few studies have also highlighted the fact that despite living in the joint family, the elderly face problem due to urban living condition and poor sanitation along with intergenerational difference and inadequate time and effort by the family in caregiving responsibility towards the elderly. Acute inadequacy accommodation excessive rents and migration of the young adults have prevented many elderly forms living with their children especially among the elderly woman, leading to distress. loneliness. increase in responsibilities and lack of caregivers. The increasing processes of industrialization, modernization and urbanization as a result of globalization and economic liberalization have had a negative impact on traditional welfare institutions and sociocultural values. These processes have also resulted in growing individualism, vulgar materialism and selfishness. In this way, a negative impact on the relations between young and the has created a situation to highlight on intergenerational relationship (Perold \& Muller, 2000). States that in the recent years, indignity, disgracefulness, embarrassment, dishonor, disheartening, disregard, indifference, injustice lack of care, psychological torture and host of negative behaviors and attitudes are reflected in the society towards elderly. In the present scenario they cannot take it for granted that their children were able to look after them when they need care in their old-age keeping in view the longer life span which implies an extended period of dependency.

It is destructive - compromising functionality. It is progressive, and irreversible. It is intrinsic, i.e. determined by internal rather than external factors. It is universal, i.e. all individuals of the same species display a largely uniform ageing pattern, with all living beings displaying the aging phenomenon (Gautam, 2010).

\section{Vedic Philosophy of Banaprastha Ashram}

Human life is full of misery. And there is the reason of this miseries. This is the supreme teaching of Lord Buddha. If we follow the teaching of Lord Buddha's philosophy from Vedic perspective. The human life will be comfortably easier. If we follow the Banaprastha Ashram philosophy in human life, the life will be an amusement journey. Life is simple, but we are complexing it from hate, greed, aversion etc. The quality of life appears in simplicity as we know, small is beautiful. 
To make our life happier and more dignified we should follow the principle of four stages of human life. Those four stages of human life a Gurukul Ashram, Grihastha Ashram, Banaprastha Ashram and Sanyans Ashram. Literally, life with Guru in school. family life, Age of research and life of renunciation (Badal B. P., 2018).

Gurukul Ashram (01- 25 Years): The first stage of human life is to know, the surroundings, parents and relatives. After knowing it all we have to departure for the formal education-Gurukul Ashram. It is also known as Bramhacharya Ashram. There we have to learn entire arts and the skills to earn wealth and fame. Gurukul Ashram is the best part of human life, where we can make our future life more dignified. Normaly, it is a complete student life as a Sanskrit verse "Kak chestha, bako dhyanam, swan nindra tathaiwa cha Alpahari Griha tyagi Bidyarthi pancha lachyanam." (Badal B. P., 2018) So, a student should be like a crow in its cleverness, meditative as crane, light sleep like a dog and vegetarian. Students should reject every comfort and has to live with Gurus on school or Universities. Students have to learn a lot that learning must be useful in next stage of human life (Badal B. , 2015).

Grihastha Ashram: (25- 50 Years) Second most important stage of human life is Grihastha Ashram. At this time human has to marry, produce a child, raise them and make them able to live in their own foot independently. At this age people have to earn wealth and fame as much as possible. At this age human has to follow worship, rituals (Pujapath, Dharmakarma) etc.

Banaprastha Ashram: (50-75 Years) The happiest stage of human life is Banaprastha Ashram. Age after 50-75. At this time human have to live every kind of bondage. At this stage of time people have to visit different places, pilgrimage etc. We have to disconnect slowly-slowly entire social relationship. This is the age of research and study (Badal B. P., 2018).

Sanyans Ashram: (75-100 Years) The final stage of human life is Sanyans Ashram. Normally the age after 75 is Sanyans Ashram. It is the time to link human soul with Almighty God. At this stage we have to end entire goals, interest, wants etc. We have to end the entire relationships. Every day we have to take a bath, we have to minimize our appetite, we have to eat only one time in day and we have to assimilate our soul into the God (Badal B. P., 2018).

In our society, we are lacking the original oriental education, western materialism has created greediness and pride in human life. So, the life is being complex. Diseases are increasing, hospitals are increasing, convectors are increasing. So happy and progressive in shadow. The knowledge of these four stages of human life is necessary. According to the philosophy of Banaprastha Ashram, after 50-year human being have to leave home and family slowly. At this 
time, we have focused our lives on our education, research and remaining activities (Gautam, 2010). It is time to leave the home but where should we go? Yes, the holy place is elderly home. The old-age home is the store of knowledge. It is a University and it is the departure starting toward the heavenly voyages. Therefore, to make the happy life in every pilgrimage we have to make elderly homes. Buddha renounce everything and became happy and enlightened.

\section{Historical development of Old-age homes in Nepal}

Pashupati Briddhasram is the first elderly home established in 1968 by the government of Nepal. History of old-age home seems very new from this statement. However, the resting places (Pati, Pauwa, Sattal) were the preliminary from the elderly homes in Nepal. Old-age home was supposed to have started from $20^{\text {th }}$ century after starting age restriction in the Almshouses (house founded by charity for poor people) (FATE). In Nepal, old-age was officially started in 1938 after the establishment of Pashupati Briddhasram (Pashupati Briddhasram- Social Welfare Center Briddhasram, 2013) This old-age home for the elderly was built as the Panchdeval (five shrines) Pakshala during the reign of King Surendra Bir Bikram Shah during the mid- to late 19th century.

In the beginning of the nineteenth century, women's and church groups began to establish special homes for the elderly persons. Often concerned that worthy individuals of their own ethnic or religious background might end their days alongside the most despised society, they establishedas the founder of Boston's Home for Aged Women (1850), explained-a haven for those who were "bone of our bone, and flesh of our flesh". Advocates for these asylums contrasted their benevolent care with the horrors of those who were relegated to the almshouse. "We were grateful," wrote the organizers of Philadelphia's Indigent Widows' and Single Women's Society, one of the nation's earliest old-age homes, in 1823, "that through the indulgence of Divine Providence, our efforts have, in some degree, been successful, and have preserved many who once lived respectfully from becoming residents of the Alms House" (Newman, 2003). The problems of senior citizens were discussed in the general assembly of the United Nations in 1979. The General Assembly submitted an action plan for the rights, welfare and interest of the senior citizens in 1992. International Conference on Population and Development (ICPD) held in 1994, which recognized the economic and social impact of population ageing in all societies.

The Labor Act, 1992, fixes minimum wage and provides for social security of workers in the formal sector. The Civil Service Act, 1992, and Regulations, 1994, have provisions related to social protection of government employees. The Local Self-Governance Act, 1999, provides for protection and development of orphan children, helpless women, the elderly, and people 
with disability. The Nepal Health Service Act, 1997, outlines various social security and health schemes for senior citizens. National human right commission NHRC in 2011 state that respects for elders and protection for weaker are the two basic human values that all societies have been promoting since the beginning of human civilization.

Following the Madrid Plan of Action on Ageing, 2002, the Government of Nepal has formulated National Plan of Action on Ageing. This action plan identifies the elderly as one of its main target groups. Although this marks an initial step in the provision of care for the elderly, institutional efforts are at its minimum as family and community are encouraged or expected to provide care to the elderly. It also aims at encouraging the provision of facilities for the elderly so as to ensure care and protection for them. Although the National Plan of Action on Ageing is a great step forward in preparing the Nepali society for a transition into an ageing society, one major issue that affects the welfare of the elderly is conspicuously absent from the plan is monitoring system.

This act was authenticated at 2063.8.8.6 (24 Nov. 2006) the aim of this act was expedient to make provisions immediately on the protection and social security of senior citizens and enhancement of trust, respect and good faith towards them by utilizing knowledge, skills, capability and experiences inherent in them which is itself a mile stone on the legal aspect of senior citizen. This act contents 32 points as rules and regulations of senior citizen. It deals that "Senior Citizen" means a citizen of Nepal having completed the age of Sixty years. It also categorized senior citizen in to two categories "Helpless Senior Citizen" and "Incapable Senior Citizen" for service providing purpose. There are no any categories on the base of age and ethnicity related. This act provides the provision of "Senior Citizen Club" a club established by senior citizens under the prevailing laws for the protection of their rights and interests but this vision is not implemented in community level.

\section{Devghat}

Devghat is a holy place of Hindus of Nepal so almost all of them want to visit of least once in their lifetime. The holy place Pilgrimage-Devghat is also holy place for old people. There are other types of old people are living individually. They manage their livelihood themselves by working i.e. by making 'Batti' (Batti-katne); the question arises is this sufficient for their survival? Thus, the study will investigate social-economic cases of living of elderly people of Devghat area (Ranjan, Bhattarai, \& Dutta, 2013). Devghat is a one of the famous religious and cultural centers in central Nepal. At the time of the 1991 Nepal census it had a population of 5786 people living in 1132 individual households. It is located at the junction of Seti Gandaki and 
Krishna Gandaki rivers. It is one of the holiest places in Hindu mythology as well as a holy place for Hindu gods. It is located 7 kilometers from Narayanghat, 20 kilometers from Sauraha and 150 kilometers southwest of the capital city Kathmandu (Bhandari, 2002). Bus service is available from the Pokhara bus station in Narayanghat city while private taxis and cars can be hired in the city. About 1,500 elders are living in these old-age homes at present (Timalsena, 2013). This is funded by the Ministry of Women, children and social welfare of Nepal and donation received from different individuals on their personal basis (Ranjan, Bhattarai, \& Dutta, 2013). Most of them are charity organizations. About 1,500 elders are living in these old-age homes at present.

This religious site has various temples and caves dedicated to Hindu gods, goddesses, and saints. Goddess Sita's cave also lies in this site. In the first of Magh every year i.e. Makar Sankranti, huge melas (gatherings) are observed. It makes it one of the largest religious melas in Nepal. Hindu pilgrims bathe at the junction of the Krishna Gandaki river well known for its rare Saligram Sheela (holy stone), which Hindu devotees' worship as Lord Vishnu. Devghat is one of the religious places that lies in central Nepal. This is the meeting point of Tanahun, Chitwan and Nawalparasi district of the country. Devghat lies $200 \mathrm{~m}$ above the sea level and the area covers inner terai and some low mountains. In northern part of this area, there is Seti, Madi, Saranghat and Chiple village development committee of Tanahun district. The holy place Devghat Dham located in Chitwan district is situated in the middle part of the district. The Jugedi and Ramnagar bazar of Chitwan district and Prithvi highway are in eastern side. Nawalparasi district is situated in the western side. This is an attractive valley in front of the hill of Tanahun district and is surrounded by rivers. The then His Majesty Government of Nepal, under section 3 of the development committee act 2013 established Devghat area. It was identified that the area covered by Devghat is 27137 ropanies, 15 annas, 1 paisa and 2 daam as per the record of land registry office in Tanahun (Gautam, 2010). Devghat Dham is situated about $144 \mathrm{~km}$ southwest of Kathmandu valley. There is vehicle facility available to reach Devghat from Narayanghat.

Devghat is spiritually and socially religious places for Hindu devotees. Most of the Hindus want to die in Devghat if they are compelled to leave the home. Due to the philosophy people want to live in Devghat. So, there are four elderly homes and many Kalpabas - private settlement for the religious purpose organized by different trusts associated with Devghat Development Committee. There were 156 Kalpabas but number of operating Kalpabas varies in time and again. Therefore, the study is focused on four elderly homes and people living in Kalpabas.

The study addresses the respecting culture of old-age people but it has missed social and economic aspects of those destitute elderlies. Major problems faced by the old couples are anxiety, 
helplessness, loneliness feeling, and increased social and cultural burdens including household ones. Their lives have become isolated. They, therefore, intended to go to better places having modern facilities (Bhandari, 2002). But they think it is better to live together with all family members rather than to move towards new place

It has also tried to get into the fact of why and what type of support the elderly people desires in their old-age and what kind of support does the elderly home provide to the elderly people. The research has also focused on why the elderly people come to old-age home pinpointing the early marriage, change in family system, poor economic condition, etc. Despite the fact that this study has highlighted the reasons behind the elderly population to come to live in Devghat old-age home, this has not set a track on which the facilities and services provided to the elderly people can be displayed and studied. The gap found in research of old-age home and elderly study is the ratio of male to female population in old-age, the ratio of male and female who are more tortured in a family, the facilities provided in any old-age home to make the home more sustainable and the hospitability provided to the old-aged people that makes them start loving the place and their life as well.

\section{Conclusion}

Old-age is not weary and gray hair; it is a matured experience learned from entire long life. Staying in an old-age is living in university, learning and sharing of education and experiences. Old-age home is blissful university of human kinds. The old-age home is supposed to be a holy place where people come to live their old-age life in their own will and in pursuing whatever they desire to. The place must be free of any kinds of ill cultures and thoughts and so is the oldage homes of Devghat. The old-age home of Devghat doesn't have any kinds of discrimination present in any homes. As the house of physically and mentally weak people, the old-age homes must be fully faired with the features that helps to strengthen the elderly and enable their sound living. In a nutshell, I conclude that the old-age homes of Devghat are normal in-terms of the lifestyle of the elderly living there, their happiness level and the facility provided to them. Lastly the major reasons behind them coming to the old-age home was rather found to be in a mixed bag form as some came there due to the social reasons and economic reasons and some due to their faith in god and in belief of getting peace after death. It must be like a complete university with entire facilities to old people for learning and sharing like in heaven or in Brindavan of vedic philosophy. 


\section{References}

Badal, B. (2015). Jestha Nagarik, Ajaka Yuwa ra Bridhaashram. Kathmandu: Niraj \& Ramsharan.

Badal, B. P. (2018). Briddhashram, Jesth Nagarik ra aajakaa yuwa (Elderly Homes) Aging Nepal (pp. 1-5). Kathmandu: Aging Nepal .

Bhandari, S. (2002). Old-Age People in elderly home: A sociological study of Devghat Samaj Kalyan Kendra, Tanahu. Kathmandu, Kritipur: Cental Department of Sociology/ Anthropology Tribhuvan University (Master's Thesis).

Deloitte. (2014). China's Senior Housing - Now and the Future. China: Deloitte China Real Estate.

Gautam, K. M. (2010). Status Report on Elderly People (60+) in Nepal on Health, Nutrition and Social Status Focusing on Research Needs. Kathmandu: Geriatric Center Nepal.

Harvard. (2014). Housing America's Older Adults-Meeting the Needs of an Aging Population. Harvard

University: President and Fellows of Harvard College. www.jchs.harvard.edu University, Joint Center for Housing Studies of Harvard.

Lunenburg, F. C. (2011). Expectancy Theory of Motivation: Motivating by Altering Expectations. International journal of management, business, and administration, V 15, N 1, 2011, Sam Houston State University.

Menezes, S., \& Thomas, T. M. (2018). Status of the Elderly and Emergence of Old-age Homes in India.

Kerala, India: International Journal of Social Sciences and Managementnt. J. Soc. Sc. Manage. Vol. 5, Issue-1: 1-4.

Newman, S. (2003). The Living Conditions of Elderly Americans. The Gerontological Society of America The Gerontologist, 99-109.

Perold, A., \& Muller, M. (2000). The Composition Of Old-age Homes in South Africa in Relation to the Residents and Nursing Personnel. Curationis March, 87-94. 
Ranjan, S., Bhattarai, A., \& Dutta, M. (2013). Prevalence of depression among elderly people living in old-age home in the capital city Kathmandu. Health Renaissance, 213-218.

Riley, S. (2005). Herzberg's Two-Factor Theory of Motivation Applied to the Motivational Techniques within Financial Institutions. Senior Honors Theses. 119 Eastern Michigan University.

Salam, A. A. (2010). Community Based Geriatraic Care in India: A perspective. Journal of the International Institute on Aging (United Nations - Malta) · January 2010, 1-16.

Timalsena, R. (2013). Factors Associated with Anxiety and Depression among Elderly Living in Old-aged Homes in Kathmandu Valley. Bhaktapur: Research Division University Grant Commission \& Nepal Institute of Health Sciences .

UNFPA. (2017). Caring for Our Elders: Early Responses India Ageing Report - 2017. New Delhi, India: United Nations Population Fund .

Verma, R., \& Khanna, P. ( 2013). National program of healthcare for the elderly in India: A hope for healthy ageing. . Haryana, India: Department of Community Medicine, .

Yadav, L. (2014). A sociological study of Old persons residing in an Old-age Home of Delhi, India. International Research Journal of Social Sciences, 21-23. 